\title{
Study to assess sub-foveal choroidal thickness in patients of pre- eclampsia through spectral domain optical coherence tomography
}

\author{
Astha Lalwani ${ }^{1 *}$, Priye Suman Rastogi ${ }^{2}$, Rehana Najam ${ }^{1}$, Ashish Chander ${ }^{2}$
}

\begin{abstract}
${ }^{1}$ Department of Obstetrics and Gynecology, ${ }^{2}$ Department of Ophthalmology, Teerthanker Mahaveer Medical College, Moradabad, Uttar Pradesh, India
\end{abstract}

Received: 22 November 2021

Accepted: 08 December 2021

\section{*Correspondence:}

Dr. Astha Lalwani,

E-mail: asthalalwanirastogi@gmail.com

Copyright: ( $\odot$ the author(s), publisher and licensee Medip Academy. This is an open-access article distributed under the terms of the Creative Commons Attribution Non-Commercial License, which permits unrestricted non-commercial use, distribution, and reproduction in any medium, provided the original work is properly cited.

\begin{abstract}
Background: Aim of the study was to assess sub-foveal choroidal thickness (SFCT) in preeclamptic patients by SD ocular coherence tomography (SD-OCT) and correlate its changes with severity of preeclampsia.

Method: This case control, observational study, conducted in department of ophthalmology in association with department of obstetrics and gynaecology. The subjects were split into two groups: study and control. Study group was further divided in to 2 groups i.e., group A (Patients with preeclampsia) and group B (Pregnant females without preeclampsia). Control group (Group C) of non-pregnant females of similar age group. Total 100 patients were taken in each group. Subjects from both study and control groups were subjected to SD-OCT and mean choroidal thickness of both eyes was noted. Data was noted and comparison of 3 groups was done.

Results: Baseline characters viz, age, period of gestation, and parity was comparable among all the groups as $\mathrm{p}>0.05$. Mean arterial pressure (MAP) was $102.72 \pm 9.81$ and $84.56 \pm 7.83$ in group A and B respectively with statistically significant difference as $\mathrm{p}<0.01$. Following a post hoc analysis, it was discovered that the SFCT of the healthy pregnancy group did not differ substantially from that of the control group, however the SFCT of the pre-eclampsia group was significantly higher than that of the control and healthy pregnancy groups.

Conclusions: Pre-eclampsia causes a greater increase in sub-foveal choroidal thickness than normal pregnancy or nonpregnant women. It has the potential to be used as a predictor or marker of pre-eclampsia severity.
\end{abstract}

Keywords: SFCT, Preeclampsia, MAP, OCT

\section{INTRODUCTION}

Pre-eclampsia can be defined as a pregnancy-related disorder characterised by increased blood pressure and proteinuria, as well as a variety of additional signs and symptoms such as oedema, vision abnormalities, headache, and epigastric pain. ${ }^{1}$ Pre-eclampsia affects about $5 \%$ of obstetric patients, with a high global death rate and a high incidence of maternal and fetal mortality and morbidity. ${ }^{2}$ Pre-eclampsia affects the ocular parameters, with pathology affecting $25-50 \%$ of patients. ${ }^{3}$ Preeclampsia is linked to an insufficient maternal blood supply to placenta, enhanced systemic blood flow resistance, a defective endothelium, despite the fact that the specific pathophysiology of the disease is unknown.
Raised pachymetry and modified curvature of cornea, as well as lowered corneal sensations and IOP, are all known ocular alterations that occur during healthy pregnancy. ${ }^{4}$ Optic nerve changes, edematous retina, central serous chorioretinopathy, haemorrhages over retina, Elschnig's pearl's, soft exudates, widespread constriction of the arterioles, and RD are all signs of preeclampsia. Reduced visual perception, photopsia and floaters, and abnormalities in visual field assessment are all possible visual complaints. ${ }^{5}$

Abnormalities in blood circulation of choroid and ischemic changes have also been described in pregnancy patients. $^{6,7}$ To test choroidal function during pregnancy, conventional techniques such as ICG, fundus fluorescein 
angiography and color Doppler USG were previously utilised. The invent and utilization of spectral-domain optical coherence tomography (SD-OCT) equipment has made it possible to analyse choroidal morphologic aspects in great detail. ${ }^{8}$ SD-OCT is an essential approach for studying choroidal alterations during preeclampsia since it is a noninvasive diagnostic procedure..$^{9,10}$

Various researchers have done studies on choroidal thickness in pre-eclamptic patients and have come out with contrasting results, few reported decreases in thickness while others reported increase in thickness of choroid in preeclamptic patients and very few studies have been done in India on this topic with none in North India. Present study was designed and conducted to assess choroidal thickness of sub-foveal region in eyes of patients of preeclampsia by SD ocular coherence tomography and correlate its changes with severity of preeclampsia, assuming Choroidal thickness could be an indicator of severity of preeclampsia and SD OCT can be an important non-invasive tool to assess the severity.

\section{METHODS}

This case control, observational study was conducted after approval from college research committee and institutional ethical committee in department of ophthalmology in association with department of obstetrics and gynaecology at Teerthanker Mahaveer medical college Moradabad. Study period was 6 months between July 2021 to December 2021 the subjects were split into two groups: study and control. Study group was further divided in to 2 groups i.e., group A (Patients with preeclampsia) and group B (Pregnant females without preeclampsia). Control group (Group C) comprised of non-pregnant females of similar age group. Study group was selected from department of gynecology and obstetrics while control group was selected from department of ophthalmology. Total of 100 patients were taken in each group.

\section{Inclusion criteria}

Pregnant females in age group of 18 years to 35 years in $3^{\text {rd }}$ trimester of pregnancy with preeclampsia (BP elevation after 20 weeks of gestation with proteinuria or any other feature of preeclampsia) as 1 group, normotensive pregnant females as another group in study groups and normal non pregnant females of similar age group for control were included in the study.

\section{Exclusion criteria}

Patients with diabetes mellitus, hlo of ocular trauma, patients with media opacities where OCT is not possible, patients with macular pathology, patients with any ocular or orbital co-morbidity, with hlo retinal surgery or hlo of vitritis, choroditis, retinitis or orbital inflammation and patients with eclampsia were excluded from the study. Those patients who refused to sign the consent were also excluded from the study.
Study group patients underwent: Mean arterial blood pressure and urine albumin.

Subjects from both study and control groups were subjected to SD OCT and mean choroidal thickness of both eyes was noted.

To avoid diurnal fluctuations in choroidal thickness, we conducted OCT scans in the morning between 8 am and 12 pm. All eye examinations and OCT scans were performed by the same experienced ophthalmologist (PSR), who used a Heidelberg Spectralis OCT scanner. A six-line radial scan with the EDI setting was used to photograph the choroid, with 100 pictures averaged per region. Before being included in the study, all scans were examined. Those having picture artefacts or incorrect choroidal limits were not allowed to participate.

Using the Spectralis OCT measuring software, thickness of choroid was calculated as the straight distance from the outer surface of retinal pigment epithelium to the sclerochoroidal contact. Measures were taken by a seasoned ophthalmologist (DL) who remained anonymous to the participants.

Data was noted and comparison of 3 groups was done.

\section{Statistical analysis}

It was done using SPSS software version 24 and the difference between groups was analyzed using ANOVA test. Pearson correlation analysis was used to find out the correlation between the variables and the parameter of $p$ was standardized at $<0.05$.

\section{RESULTS}

Baseline characters viz. age (in years), period of gestation (in weeks) and parity was comparable among all groups as $\mathrm{p}>0.05$. Mean MAP was $102.72 \pm 9.81$ and $84.56 \pm 7.83$ in group A and B respectively. When mean MAP was compared among study groups using $t$ test, it was found to be significant statistically $\mathrm{p}<0.01$ (Table 1 and Figure 1).

Table 1: Baseline data among study subjects $(\mathrm{n}=100)$.

\begin{tabular}{|c|c|c|c|c|}
\hline Variables & $\mathbf{A}$ & B & $\mathbf{C}$ & $\begin{array}{l}\mathbf{P} \\
\text { value }\end{array}$ \\
\hline $\begin{array}{l}\text { Age } \\
\text { (years) }\end{array}$ & $\begin{array}{l}31.38 \pm \\
4.02\end{array}$ & $\begin{array}{l}32.21 \pm \\
3.37\end{array}$ & $\begin{array}{l}30.98 \pm \\
4.51\end{array}$ & 0.31 \\
\hline $\begin{array}{l}\text { Period of } \\
\text { gestation } \\
\text { (weeks) }\end{array}$ & $\begin{array}{l}34.01 \pm \\
2.92\end{array}$ & $\begin{array}{l}33.86 \pm \\
3.14\end{array}$ & NA & 0.68 \\
\hline Parity & $\begin{array}{l}2.52 \pm \\
1.18\end{array}$ & $\begin{array}{l}2.11 \pm \\
0.83\end{array}$ & $\begin{array}{l}2.36 \pm \\
1.08\end{array}$ & 0.22 \\
\hline $\begin{array}{l}\text { MAP } \\
\text { (mmHg) }\end{array}$ & $\begin{array}{l}102.72 \pm \\
9.81\end{array}$ & $\begin{array}{l}84.56 \pm \\
7.83\end{array}$ & NA & $<0.01 *$ \\
\hline $\begin{array}{l}\text { Albumin } \\
\text { (g/dl) }\end{array}$ & $\begin{array}{l}2.31 \pm \\
0.68\end{array}$ & $\begin{array}{l}1.09 \pm \\
0.24\end{array}$ & NA & $<0.01 *$ \\
\hline
\end{tabular}

*Statistically significant 


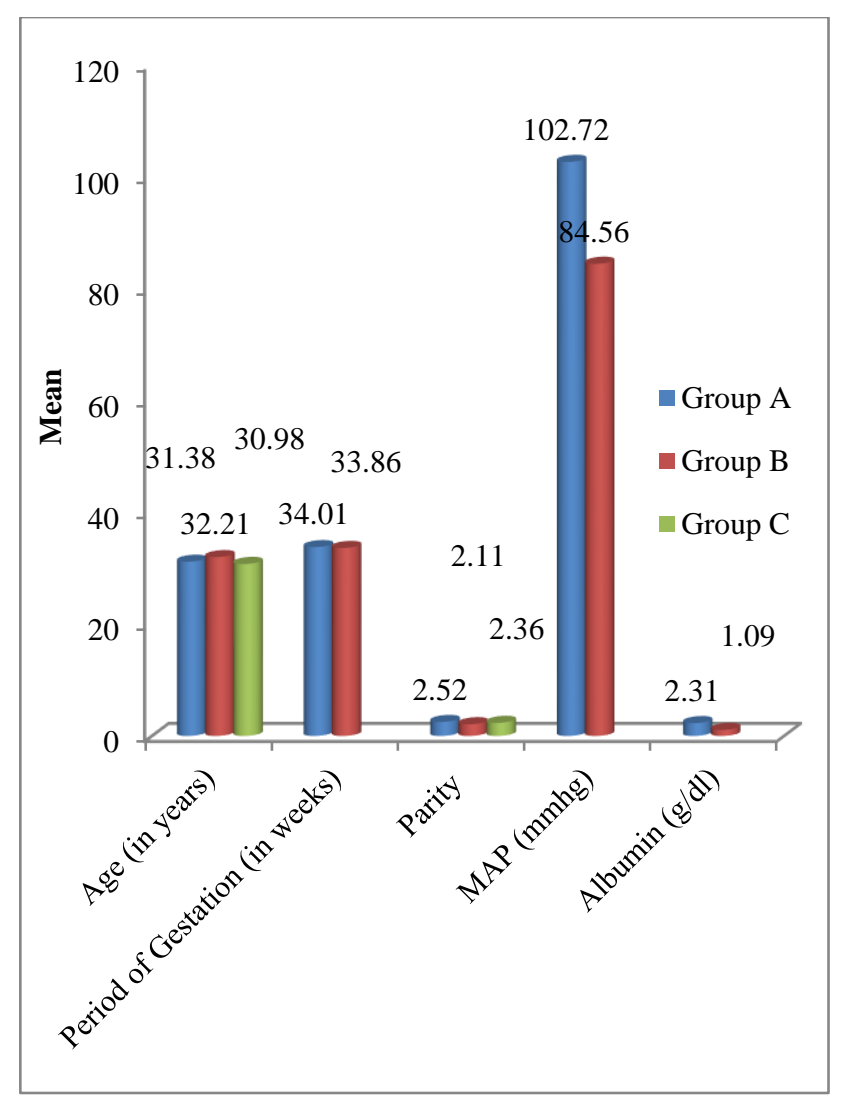

Figure 1: Baseline data among the study subjects.

Mean SFCT $(\mu \mathrm{m})$ was $378.23 \pm 20.48,294.59 \pm 18.03$ and $257.12 \pm 22.43$ in group $\mathrm{A}, \mathrm{B}$ and $\mathrm{C}$ respectively. When mean SFCT $(\mu \mathrm{m})$ was compared among the study groups using ANOVA test, it was found to be statistically significant as $\mathrm{p}<0.01$. Following a post hoc analysis, it was discovered that the SFCT of the healthy pregnancy group did not differ substantially from that of the control group, however the SFCT of the pre-eclamptic group was significantly more than of the control and healthy pregnancy groups (Table 2 and Figure 2).

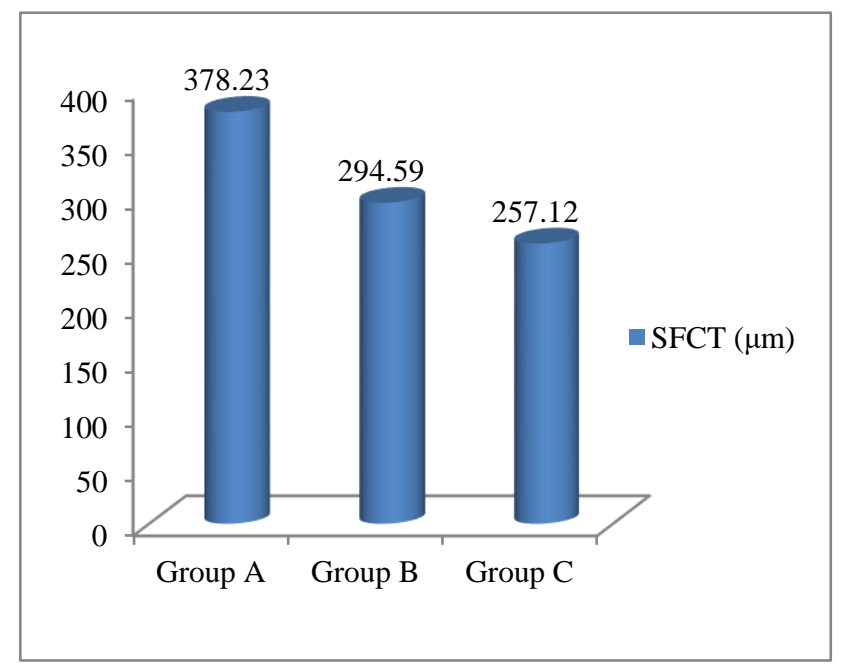

Figure 2: Comparison of SFCT (sub-foveal choroidal thickness) among the study groups.
Table 2: Comparison of SFCT (sub-foveal choroidal thickness) among the study groups.

\begin{tabular}{|lll|}
\hline Variables & SFCT $(\boldsymbol{\mu m})$ & \multirow{2}{*}{ P value } \\
\hline Group A & $378.23 \pm 20.48$ & \\
\hline Group B & $294.59 \pm 18.03$ & $<0.01 *$ \\
\hline Group C & $257.12 \pm 22.43$ & \\
\hline *Statistically significant & \\
\hline
\end{tabular}

According to Pearson correlation analysis, significant positive correlation was found when SFCT and MAP were compared $(\mathrm{r}=0.57, \mathrm{p}<0.01)$ as well as when SFCT and albumin were compared $(\mathrm{r}=0.38, \mathrm{p}=0.003)$ (Table 3$)$.

Table 3: Correlation between SFCT and MAP in group A.

\begin{tabular}{|lll|}
\hline Variables & $\begin{array}{l}\text { SFCT and } \\
\text { MAP }\end{array}$ & $\begin{array}{l}\text { SFCT and } \\
\text { albumin }\end{array}$ \\
\hline R value & 0.57 & 0.38 \\
\hline P value & $<0.01^{*}$ & $0.003^{*}$ \\
\hline
\end{tabular}

*Statistically significant

\section{DISCUSSION}

The variations in SFCT between three groups were investigated in this study: Pregnancy with pre-eclampsia, Pregnancy without pre-eclampsia, and non-pregnant women. Relationship of SFCT with mean arterial blood pressure was also investigated.

Baseline characters viz. age (in years), period of gestation (in weeks) and parity was comparable among all the groups as $\mathrm{p}>0.05$. Mean MAP was 102.72 \pm 9.81 , $84.56 \pm 7.83$ and $88.16 \pm 8.19$ in group $\mathrm{A}, \mathrm{B}$ and $\mathrm{C}$ respectively. When mean MAP was compared among the study groups using ANOVA test, it was found to be statistically significant as $\mathrm{p}<0.01$ in this study. Similar results were reported by Sharudin et al, Benfica et al and Kim et al in their studies. ${ }^{11-13}$

Pregnant women had a larger sub-foveal choroidal thickness than non-pregnant women in our study. This discovery is in line with the findings of earlier research, such as those by Sayin et al and Atas et al who claimed that larger sub-foveal choroidal thickness in pregnancy was attributable to significant hormonal, metabolic, hemodynamic, and other physiological alterations. ${ }^{14,15}$ Both authors believed that increased choroidal thickness was caused by decreased vascular resistance and increased blood flow in choroidal veins.

Pre-eclampsia patients had thicker sub-foveal choroidal tissue than typical pregnant women, according to our findings. Evcimen et al and Benfica et al found similar results when comparing choroidal thickness in preeclampsia patients and healthy pregnant women. Severe pre-eclamptic patients had the highest choroidal thickness parameters, according to both authors. They theorized that pre-greater eclampsia's sub-foveal choroidal 
thickness was linked to raised vascular levels of total vascular endothelial growth factor in pre-eclampsia pregnancies than in normal pregnancies, consequently causing endothelial cell malfunction and hyperpermeability of choriocapillaris. ${ }^{12,16}$

In our study, significant positive correlation was found between SFCT and MAP ( $\mathrm{r}=0.57, \mathrm{p}<0.01)$. Sharudin et al in their study reported significant positive correlation between SFCT and MAP. ${ }^{11}$ Ahn et al found that individuals with severe systemic hypertension had a significant increase in sub-foveal choroidal thickness. This could be attributed to alterations in choroidal permeability causing a buildup of interstitial fluid in the choroid. ${ }^{17}$

The cross-sectional design of our study has some limitations, such as the fact that we can only assess choroidal features in the last trimester of pregnancy. We did, however, exclude pregestational and gestational diabetic patients or patients with chronic hypertension from the analysis to reduce the possibility of confounding factors.

To eliminate diurnal changes, we conducted all OCT examinations in morning and did not take in to consideration, participants with eyes having any amount of refraction and with a spherical equivalent which is higher than 1.0 diopters.

\section{CONCLUSION}

Pre-eclampsia causes a greater increase in sub-foveal choroidal thickness than normal pregnancy or nonpregnant women. This metric likewise rises in lockstep with recognized markers of pre-eclampsia severity. It has the potential to be used as a predictor or marker of preeclampsia severity. More prospective studies with a bigger sample size are needed to confirm these findings and determine whether choroidal thickness may be used as a predictor of preeclampsia severity.

Funding: No funding sources

Conflict of interest: None declared

Ethical approval: The study was approved by the Institutional Ethics Committee

\section{REFERENCES}

1. Sibai B, Dekker G, Kupferminc M. Pre-eclampsia. Lancet. 2005;365(9461):785-99.

2. Sheth BP, Mieler WF. Ocular complications of pregnancy. Curr Opin Ophthalmol. 2001;12(6):45563.

3. Schultz KL, Birnbaum AD, Goldstein DA. Ocular disease in pregnancy. Curr Opin Ophthalmol. 2005;16(5):308-14.
4. Yenerel N, Kucumen R. Pregnancy and the eye. Turk J Ophthalmol. 2015;45:213-9.

5. Jaffe G, Schatz H. Ocular manifestation of preeclampsia. Am J Ophthalmol. 1987;103:309-15.

6. Iida T, Kishi S. Choroidal vascular abnormalities in preeclampsia. Arch Ophthalmol. 2002;120:1406-7.

7. Valluri S, Adelberg DA, Curtis RS, Olk RJ. Diagnostic indocyanine green angiography in preeclampsia. Am J Ophthalmol. 1996;122:672-7.

8. Spaide RF, Koizumi H, Pozonni MC. Enhanced depth imaging spectral-domain optical coherence tomography. Am J Ophthalmol 2008;146:496-500.

9. Neudorfer M, Spierer O, Goder M. The prevalence of retinal and optical coherence tomography findings in preeclamptic women. Retina. 2014;34:1376-83.

10. Zhang J, Wang H, Yu Q, Tong Q, Lu Q. Enhanced depth imaging optical coherence tomography: a new way measuring choroidal thickness in pregnant women. J Ophthalmol. 2017:8296574.

11. Sharudin SN, Saaid R, Samsudin A, Mohamad NF. Subfoveal choroidal thickness in pre-eclampsia. Optom Vis Sci. 2020;97(2):81-5.

12. Benfica CZ, Zanella T, Farias LB, Oppermann ML, Canani LH, Lavinsky D. Choroidal thickness in preeclampsia measured by spectral-domain optical coherence tomography. Int Ophthalmol. 2019;39(9):2069-76.

13. Kim JW, Park MH, Kim YJ, Kim YT. Comparison of subfoveal choroidal thickness in healthy pregnancy and pre-eclampsia. Eye. 2016;30(3):349-54.

14. Sayin N, Kara N, Pirhan D. Subfoveal Choroidal Thickness in Preeclampsia: Comparison with Normal and Nonpregnant Women. Semin Ophthalmol. 2014;29:11-7.

15. Atas M, Acmaz G, Aksoy H, et al. Evaluation of the Macula, Retinal Nerve Fiber Layer and Choroid in Pre-eclampsia, Healthy Pregnant and Healthy Nonpregnant Women Using Spectral-domain Optical Coherence Tomography. Hypertens Pregnancy. 2014;33:299-310.

16. Evcimen Y, Onur IU, Cengiz H. Optical Coherence Tomography Findings in Pre-eclampsia: A Preliminary Receiver Operating Characteristic Analysis on Choroidal Thickness for Disease Severity. Curr Eye Res. 2019;44:916-20.

17. Ahn SJ, Woo SJ, Park KH. Retinal and choroidal changes with severe hypertension and their association with visual outcome. Invest Ophthalmol Vis Sci. 2014;55:7775-85.

Cite this article as: Lalwani A, Rastogi PS, Najam $\mathrm{R}$, Chander A. Study to assess sub-foveal choroidal thickness in patients of pre-eclampsia through spectral domain optical coherence tomography. Int $\mathbf{J}$ Reprod Contracept Obstet Gynecol 2022;11:31-4. 